\title{
Insolvency and the Role of Auditors
}

\author{
Owolabi Sunday Ajao ${ }^{\mathrm{a}}$, Uhuaba Okezie ${ }^{\mathrm{b} *}$ \\ a owolabis@babcock.edu.ng \\ b uhuaba0367@pg.babcock.edu.ng \\ ${ }^{a}$ Department of Accounting, Babcock University, Ilishan Remo, Nigeria \\ ${ }^{b}$ Department of Accounting, Babcock University, Ilishan Remo, Nigeria
}

\begin{abstract}
Globally, the understanding of the role of auditors has been a complex phenomenon especially the contents and interpretation of financial statements. The perceived role of auditors in protecting clients interest against fraud, insolvency, and other matters of great concern to the shareholders and other interest groups have been a sensitive discuss that have generated strong debates in the literature. In contributing to this issue and extending the frontiers in this regard, this study examined insolvency and the role of auditors. To achieve the objective of this study, an exploratory research design was adopted, as some journals, periodicals, and other materials related to the topic were reviewed. Consequent to the reviews, the study revealed that signals of insolvency of corporate organization are detectable if the auditors are thorough and exercise professional due diligence and care in carrying out the audit assignments. The study recommended that the international auditing standards (IAS) should consider including in the standards, such sensitive variables as fraud and insolvency for special treatment and reporting in the auditing standards and guidelines. While auditors' independence should not be compromised for whatsoever reasons, the international auditing standards should mandate auditors to conduct a predictive analysis of clients' going-concern health condition diagnostic analyses to give respite and significant comfort and assurance to investors, and other financial statement users who might rely of the auditor's reports in making informed investment decisions.
\end{abstract}

Published by IJRP.ORG. Selection and/or peer-review under responsibility of International Journal of Research Publications (IJRP.ORG)

Keywords: Auditors; Auditors independence; Due diligence and car; Expectation gaps; Insolvency; International accounting standards.

\subsection{Introduction}

Periodically, the auditors' clients face some financial distress that could easily be resolved, while some others may lead to insolvency or even bankruptcy. While proficiency in liquidity management is germane, it is believed that global and industries competitiveness create avenues for efficient and optimal resource utilization to remain relevant in the industry while creating space for insolvency and bankruptcy for unprofitable corporate bodies who may wish to blame auditors for managerial inefficiencies (Cenciarelli, Velia, Giulio \& Allegrini, 2018; Chen, Yang \& Yi-Fang, 2020). Managerial recklessness, insider dealings, and fraudulent activities, and managerial ineptitude had caused the abrupt collapse of some high profile corporate bodies, yet in some other cases, incidents of complexities and uncertainties have been responsible. Auditors have always been blamed for any form of the financial crisis and have faced series of litigations when their clients fail to replicate the clean report of their statutory auditors (Berglund, Eshleman \& Guo, 
2018). It is expected that the realities as reported by the statutory auditors do not march the economic realities on the ground. One thing is clear, in most cases, there is a wide expectation gap between what the shareholders and other stakeholders expect and the guideline as stipulated by the International Auditing Standards which auditors must be following.

When an incident of solvency is the case, there is always alleged failures and complacency on the part of auditors. However, Cao, Jian, Thomas, Kubick, Adi and Masli (2017) posited that it is rather unfortunate that despite decades of auditors efforts to educate their clients as contained in the engagement letter, investors, regulators, shareholders and other stakeholders about the technicalities and limitation of audit, users of financial statements as a product of audit report depicting clean opinions as meaning viability and management probity.

\section{Insolvency and Audit Predictive Models:}

Researchers have made efforts to investigate and create nexus between insolvency and solvency of corporate bodies. In 1908, Rosendale tried to investigate risks associated with insolvency among corporations and this was based on available information of the company's current assets (Beaver, 1968; Prusak, 2018; Cenciarelli, Greco \& Allegrini, 2018). Others made few attempts predicting possible cause of insolvency among them include Ramser and Foster in 1931 as well as (Back et al., 1997, and Beaver (1966) who explored multiple financial indicators of discriminative power for each measures, but the level of correct prediction were never absolute (Prusak, 2018). However, in 1968, Altman'S (Z-score) publication made a hallmark breakthrough, where impact of several indicators on the financial health condition of companies were evaluated using a combination of variables ion a single model of (Z-score) using a technique of multivariate linear discriminant analysis to accomplish this evaluation (Altman, 2018). According to Altma, Malgorzata, Erkki and Arto-Suvas (2017), Altman alongside other scientists thereafter developed many other models devoted to many American corporations and outside the United State of America countries (Altman \& Narayanan, 1997). Ultimately Altman's multivariate linear discriminate analysis made most popular technique developed for corporate insolvency signals and bankruptcy forecasting models.

However, in $1970-1980$ s, strong criticisms were generated following some scholars flaws found in linear multivariate analysis and brought logit and probit analysis as a better insolvency and corporate bankruptcy forecasting, using linear programming, models of recursive division, also the cluster analysis or the classification trees (Hardle, Rouslan \& Dorothea, 2004; Prusak, 2018; Ohlson, 1980; Zavgren, 1983). Yet in 1990s, the statistical and analytical techniques were introduced to a more sophisticated techniques in analyzing more robust and larger data, while efforts to isolate auditors in the problem of insolvency. Some scholars have been busy to investigate empirically, the possibilities of using statistical predictive models to forecast early predicting signals of insolvency and bankruptcy of entities. The recent methods have been advanced, soft computing techniques, using allocation that enables the implementation of advanced computational procedures (Korol, 2013); artificial neural networks using genetic algorithms (Shin \& Lee, 2012), fuzzy logic, and fashionable swarm algorithms also called ant colony algorithm (Martin, Lakshmi \& Venkatesan, 2014, Prusak, 2018. Most recently some studies have explored the use of PART algorithms, random forest, and support vector machine models in making portent predictions using new information technologies now in vogue (Chen, Xiumin, Xin, 2013, Cultrera, Xavier, 2016). Beyond the empirical predictions of insolvency, the debate on insolvency and the role of auditors has become a critical issue in contemporary literature as prior studies have shown divergent opinions and mixed thoughts on the liability and culpability of auditors (Chen, He, Ma \& Derrald, 2016). While some studies have strongly thought that auditors should be held liable and responsible, as the unqualified financial report implies solvency of the clients (Futsler, Nickell, Sean \& Robb, 2016), other studies think otherwise (Chen, Eshleman \& Soileau, 2017). This group of studies of proponents and opponents of culpability of auditors is considered herein:

Proponents of Auditors Culpability: A school of taught have auditors to blame for insolvency of their clients. For instance, Guiral, Rodgers, Ruiz and Gonzalo (2018) opined that auditors have failed in all 
ramifications in their inability to dictate fraud and prevent errors, high level of professional incompetence, and reckless display of ineptitudes (Hardle, Rouslan \& Dorothea, 2004). Hardle et al., (2004) argued that some auditors have lost their audit independence and compromised their integrity to lofty romance of petty pecks from the manager of their clients against the detriment of the innocent shareholders the auditors are paid supposedly to protect (Guiral et al., 2017). The case of Enron and Arthur Andersen was a clear case of betrayal of confidence of the Arthur Andersen who ought to protect the interest of the shareholders as the auditors (Futsler et al., 2016). Ittonen, Per and Wong (2017) went further than this single case of Arthur Andersen has brought huge disgrace to the auditors and accounting profession globally. A major undoing of Arthur Andersen was the duality role of performing both internal and external audit function for Enron, this facilitated in compromising its independence as an external auditor. Some auditors and auditing firms have failed using available information innovations and enabling analytical information technologies that could significantly improve the quality of auditing exercise.

Apparently, auditors' inability to perceive possible early red flags or liquidation warnings and impending insolvency or bankruptcy of corporate bodies portends auditors' failure and should be culpable of insolvency of their clients (Jiang, Hu, Wang, Jiang \& Wu, 2020). Most auditors are careless lack appropriate focus on financial reporting, financial fraud pandemic, which in itself is endemic among audit firms globally, expensive mistakes of misstatements a prime leading indicator of corporate bankruptcy and eventual collapse (Kausar, Richard, Christine \& Tan, 2017). The auditors' report is not comprehensive enough in addressing the concern of fraud investigation and the reliability of the audit report left nothing to be desired, primarily the aim of the auditing exercise to lend credibility and integrity to the activities of the management, which is far and above reckless unreliable expression of opinion (Koh \& KinWai, 2017).

According to Kausar and Lennox (2017), the sole objective of auditors is to enhance stakeholders trust, contribute to societal confidence from the perspective of financial statements (Ole-Kristian, Hu \& Zhao, 2017; Opoku, Chizema, 2017; Philippe, 2015). Auditors must act as the umpire and particularly guard and protect stakeholders' interest rather than betraying such confidence, stakeholders who have suffered huge capital loss resulting from irredeemable insolvencies cannot accept any excuses of vulnerability of incompetence and shallow practices of professional laxity of auditors (Guiral, Rodgers, Ruiz \& Gonzalo, 2018; Rodgers, Guiral \& Gonzalo, 2019).

Opponents of Auditors Culpability: On the contrary, there are other antagonists' studies who think that auditors are rather victims of the ignorance of stakeholders who do not have a full understanding of the auditors' limitations, as auditors stick to auditing standards guiding auditing processes and procedures. These later school of thought in support of auditors believe that professional expression of true-and-fair view opinion by the statutory auditors cannot predictably be foretold the obvious vicissitudes prevailing in normal business activities that can effects the fortunes of clients even after the audit report that happens once in whole a year (Read \& Yezegel, 2016). Read et al., (2016) posited that auditor in expressing fair and fair opinions, cannot prognosticate the possible effects of micro and macro-economic indexes, political and economic factors, and exogenous dynamics like the global financial crisis, after all, no auditors financial reports foresaw the recent COVID-19 pandemic and its devastating effects on corporate organizations and on nations' economies (Jiang, Hu, Wang, Jiang \& Wu, 2020).

Similarly, Seising (2018) and Sotti (2018) submitted that some law cases brought against statutory auditors prompt immediate reactions when there are shreds of evidence of sharp stock dips which on many occasions as ill-conceived business procurements and the dynamics of forces of demand and supply. In spite of the opinions of the various scholars in the prior studies, the researcher has a strong belief that signals of insolvency of a corporate organization are detectable if the auditor is thorough and exercise professional due diligence and care in carrying out the audit assignment. Though the standards were not specific on insolvency reporting, however, even when the case of culpability of the auditors cannot be precisely confirmed, yet after expensive audit exercise, a professional auditor will perceive during the audit procedure after performing the required liquidity test and other sustainability tests that something is right to point out at possible and 
potential financial distress ahead. The researcher believes that some key financial rations using Z-score will reveal the economic and financial health condition of the client and early professional advice and waning could possibly avert insolvency.

\subsection{Literature Review}

\subsubsection{Insolvency}

The concept of insolvency means a state of financial illiquidity and distress such that a corporate entity or person is not able to settle its indebtedness (Seising (2018). In some situations, this may possibly lead to litigations and court proceedings where legal action may be taken against the company or person; in this case an insolvent entity or insolvent person in the eye of the law. This equally could lead to setting the assets of the insolvent person to be liquidated in an effort to the settlement of the outstanding debtors. Insolvency is a reflection of a total failure of the external auditors who are in retainership by the company, since the auditor provides an informative credence for the security and reliability of the operation/activities of the managers (Pedrosa, Aurea \& Francisco, 2018). According to Rodgers, Guiral and Gonzalo (2019), auditors ought to provide an umpire series of independent professional service on the economic health condition of the clients and liquidity certification inclusively covered. When the security of the stakeholders, investors, fund lenders, creditors, government tax obligations, and other invested stakeholders are not fully guaranteed, such investments and portfolio diversification decisions based on such audit reports, when there are cases of insolvency after all these decisions, the auditors should be blamed.

However, Sanchez-Sarrano, Alaminos, Francisco and Callejon-Gil (2020), differed from the point of view expressed by Pedrosa et al (2018) argued that the audit standards should be held responsible for not accommodating issues that will guarantee solvency reporting. The International Auditing Standards should be more comprehensive and more inclusive to protect the interest of investors and other stakeholders.

\subsubsection{The Role of Auditors}

The role of auditors in the issue of insolvency of clients is rather complex and multifaceted considering the huge expectation gaps between the auditors' guiding standards and the stakeholders' expectation perceptions. The auditors' role perceptions from the shareholders and other financial statement users in regards to insolvency are wide considering widespread users with different expectations and go beyond roles/responsibilities of the auditor as assigned by statute and the auditing professional standards. These misconstrued roles of the auditor in the case of insolvency by the shareholders have become far-reaching of calling a dog names to crucify it (Read \& Ari-Yezegel, 2018). It is normal for such an expectation gap to exist since audit knowledge seem strange to some stakeholders. Such gaps exist in many areas of the auditor's work including the responsibilities of the auditor regarding fraud and errors in his audit of financial statements. Furthermore, from the companies' management perspective, the Shareholders have expectations that auditors do not want to report beyond the current practices in the profession and indeed beyond the scope and bound defined by the statutes and standards. The shareholders in high expectation of auditors' prevention of fraud, absolute prove in an audit report of absolute solvency, and liquidity buoyance as part of the audit report in most cases do not align and bring into line the statutory restrictions of the auditors. This misunderstanding and misconceived roles of the auditor by the shareholders are rather unfortunate (Sotti, 2018)

\subsubsection{International Audit Standards and Nigerian Standards on Auditing}

International Auditing Standards: The international auditing standards have not made any specific pronouncement on the issue of the role of auditors in clients' solvency in clear terms, however, it is implied from the pronouncement of the standards. ISA 250 Consideration of laws and regulations in an audit of financial statements requires the auditor to: (a) obtain a general understanding of the applicable legal and regulatory framework and how the entity is complying with that framework. This is part of obtaining an understanding of the entity and its environment as required by ISA 315; (b) obtain sufficient appropriate audit 
evidence in respect of compliance with those laws and regulations which might be expected to have a direct effect on material amounts and disclosures in the financial statements; (c) perform the following audit procedures to help identify such instances of non-compliance: make inquiries of management as to whether or not the entity is complying with the relevant laws and regulations. inspect any correspondence with the relevant authorities; (d) during the audit, remain alert to the possibility that other audit procedures might bring instances of non-compliance to the auditor's attention; (e) obtain written representations from management that all known instances of non-compliance or suspected non-compliance have been disclosed to the auditor; (f) document all identified or suspected instances of non-compliance and the results of discussions with management and/or other parties (Bauweraerts, 2016; Guiral, Rodgers, Ruiz \& Gonzalo, 2018).

The quality of auditors reporting is critical to the value of the financial statement and to the continued relevance of the auditing profession. According to International Auditing and Assurance Standards Board (IAASB), the new and revised Auditor Reporting Standards lay the foundation for the future of global auditor reporting and improved auditor communications (Amin, Keval, Krishman \& Yang, 2014). The requirements of the accounting standards have become more complicated over time, leaving some stakeholders and shareholders out of their depths when it comes to analyzing financial statements. On 15 January 2015, IAASB released the New and Revised Auditor Reporting Standards, effective for audits of financial statements for periods ending on or after 15 December 2016; early adoption is permitted (Jiang, Hu, Wang, Jiang \& Wu, 2020). These new and revised standards, seen as a first step towards enhanced reporting, are expected to have a profound impact on the accounting sector and corporate governance in the years to come. The 2008 global financial crisis heightened the scrutiny on corporate governance practices and fueled further impetus to gain greater insights into the audited financial statements of listed companies and other public interest entities. For instance, Sarbanes-Oxley Act of 2002. The accounting scandals began by the Enron collapse and extending to such giant companies as WorldCom, Xerox, and Tyco, caused a backlash in the USA, resulting in legislation being signed into law by the US President in July 2002. The Sarbanes-Oxley Act is the first accounting law passed by the US since the Securities and Exchange Act of 1934 (Munoz-Izquierdo, Camacho-Minano, Segovia-Varga \& Pascua-Ezama, 2019).

Nigerian Standards on Auditing: The Nigerian Standard on Auditing (NSA) deals with independent auditor's overall responsibilities when conducting an audit of financial statements in accordance with NSAs. Specifically, it sets out the overall objectives of the independent auditor and explains the nature and scope of an audit designed to enable the independent auditor to meet those objectives. It also explains the scope, authority, and structure of the NSAs and includes requirements establishing the general responsibilities of the independent auditor applicable in all audits, including the obligation to comply with the Nigerian standards on auditing (Okpala, 2015). As the basis for the auditor's opinion, NSAs requires the auditor to obtain reasonable assurance about whether the financial statements as a whole are free from material misstatement, whether due to fraud or error. Reasonable assurance is a high level of assurance. It is obtained when the auditor has obtained sufficient appropriate audit evidence to reduce audit risk (that is, the risk that the auditor expresses an inappropriate opinion when the financial statements are materially misstated) to an acceptably low level. However, reasonable assurance is not an absolute level of assurance, because there are inherent limitations of an audit which result in most of the audit evidence on which the auditor draws conclusions and bases the auditor's opinion being persuasive rather than conclusive (Feng \& Chan, 2014; Lioukas \& Reuer, 2015).

\subsection{Theoretical Review}

The examination of insolvency and the role of auditors is underpinned in the theory of lending credibility and theory of inspired confidence. These theory were considered because of their relevance to insolvency and auditors in relation to the perceived expectation of the users of the financial statement audited by the auditors. 


\subsubsection{The Lending Credibility Theory:}

The lending credibility theory was developed by Watts and Zimmerman, in the year 1996 aimed at putting reputation and trustworthiness to financial statement prepared by the management for the shareholders and other interested stakeholders (Ohlson, 1980). As expected the basic assumption of conflict of interest is prevalent in the corporate bodies, as the financial reporsd are prepared by one of the interested parties (agents) and the other party (principal) depend on the services of an independent professional (statutory auditors) to ascertain the veracity of the financial statement (Goncharov, Werner \& Zimmermann, 2009). In doing this umpire financial job function, credibility is given to the financial statement after the auditor has carried out an audit exercise and express an opinion. Accordingly, the stakeholders believe it is one of the main objectives of auditing; it is the addition of credibility to the financial statements and confirm that the report is free of material misstatement, fraud, and errors. If stakeholders such as stockholders, government, or creditors have to make their judgments based on the information they receive, they must have faith that this is a fair representation of the economic value and performances of the organization. In audit research terms an audit reduces the "information asymmetry", management knows more than the stakeholders (Carson, Neil \& Zhang, 2016; McEvily, Zaheer \& Kamal, 2017).

\subsubsection{Theory of Inspired Confidence}

The theory of inspired confidence aimed to instill confidence in rational expectations (Geiger, Raghunandan \& Richccardi, 2014). The theory suggests that shareholders who are inspired to trust the financial statement after it has been certified by the auditors, who are hired by the shareholders. The desire for audit services is a consequence of possible conflict of interest between the owners of the corporation and those of the managers (agents) who are hired to act on behalf of the owners (principal). The owners demand accountability and reliability of the true stewardship report prepared by the managers, who incidentally have their own interest and working in all purposes protecting their own interest to the detriment of the shareholders. According to McEvily et al., (2017), confidence and trust are supreme, and if the auditors' trust and confidence is betrayed, the whole essence of audit exercise is efforts in futility. If the shareholders and the user of financial statements cannot trust the reliability and accuracy of financial statements certified by the auditors, it becomes a big issue. Apparently, the users of financial statements do not expect a case of insolvency from clients audited and given a clean bill of health report by the statutory auditors.

\subsection{Empirical Review}

Okpala (2015) studied the effects of Stamatis generic model applications on audit quality in Nigeria aimed at addressing the bad image of the auditors and as well improve the quality of audit exercise and reliance on the credibility of audit reports. Survey research design, using a structured questionnaire was employed in the study. A population of 916 licensed audit firms has consisted of which a sample of 683 copies of the questionnaire was administered to selected respondents. A total of 641 questionnaires were retrieved from the respondents, representing $94 \%$ (percent). The validity was carried out by certified quality management, while the reliability was confirmed based on the Cronbach alpha reliability test of $85 \%$ from the pretest analysis carried out. The study explored the use of Pearson product-moment coefficient correlation to analyze the hypotheses. The study found that a positive and statistically significant relationship existed between Stamatis generic models and degree of implementation and that application of Stamatis generic models and audit quality. Furthermore, the study showed that the quality of audit in Nigeria had not shown much quality because of ignorance, inexperience, and low auditing resources at the disposal of the auditors. It recommended that audit firms in Nigeria need to employ Stamatis generic models (SGM) in order to improve the quality of audit reports to the satisfaction of clients.

Similarly, Sanchez-Serrano, Alaminos, Francisco and Callejon (2020) investigated new audit opinions using predictive models for corporate and subsidiaries after consolidating financial statements. The study adopted an artificial neural network technique using a sample of selected Spanish companies, also the study employed 
a multilayer perception index for the study. In conclusion, it was shown that the development model managed to evaluate and forecast the audit opinion gave an accuracy of $86 \%$ (percent). Furthermore, that the study exhibited a result showing that there existed a significant difference concerning important audit variable audit opinion prediction for each item in the statement of financial position and statement of profit or loss account. That in most cases audit size, audit board members being used as audit explanatory variables of the predictive analysis.

Chen, Yang and Yi-Fang (2020) investigate the relationship between professional training, higher education qualification, and audit quality and performance of audit firms in Taiwan. The study employed the use of curvilinear effects of advanced audit academic qualification on the quality and performance of auditors. A cross-sectional multiple regression equation was explored to test the study hypotheses, which showed that advanced academic of audit education attainment had a positive association with quality of audit and performance of auditors, that professional audit training moderated the relationship between advanced academic attainment and audit professional performance. Furthermore, advanced audit academic attainment exhibited a curvilinear effect on operational performance with an inverse U-shape association using national audit firms and a U-shaped association for regional and local audit companies. The study results rightly implied that the quality of audit in relation to audit operating performance is not analyzed in the study due to the non-availability of data. Furthermore, advanced audit attainment had a positive relationship with audit operating performance of audit firms while audit skills and advanced academic attainment improved audit operating performance in Taiwan.

Rodgers, Guiral and Gonzalo (2019) examined the case of trusting or distrusting auditor opinion. The study of Rodgers, Guiral and Gonzalo (2019) employed the use of throughput model of analysis to investigate the relationship between trusting and distrusting of audit opinion based on express of an opinion of qualified or non-qualified financial statements. Exploratory research design was employed by the researchers. The valuation was based on the fact that auditor's assessments of clients' financial statements should give the auditor to know the going concern status of the company in terms of fraud, insolvency, or bankruptcy. The sustainability of the clients in the capital market is off essence to be contained in the auditor's report. The result of the review revealed that going concern opinion of the auditor had serious implications for the auditing profession, the auditing firms, and the general public use and rely on that audit opinion for investment and other important purposes. The throughput model employed was able to illustrate how diverse trust position is aligned with a particular opinion of the auditor for the users' decision making, hence trust and distrust is quite an important component from the point of view of the investors and other stakeholders who rely on auditor opinion.

The study of Munoz-Izquerdo, Camacho-Minano, Segovia-Varga and Pascual-Ezama (2019) investigated the combination of anticipated financial distress ratios in predictive purposes of auditor clients. The study complemented a prior study that provided a predictive accuracy of $80 \%$ by using disclosures contained in audit report an analysis of audit reports for better predictive purposes and the same predictive accuracy was achieved. The study adopted three artificial intelligence techniques (Part algorithms, random forest and support vector machine), the predictive capability of extracted data from the financial statement was analyzed and the results revealed for the following, audit opinion, identification of material misstatements, reasonable disclosures was obtained from the comments. It suggested that insolvency and or bankruptcy can be accurately be predicted with an extensive and rigorous audit exercise using the right predictive models and explanatory variable.

\subsection{Methodology}

Insolvency and the role of auditors were extensively reviewed in this study. In carrying this task, exploratory research design was adopted, using prior studies in the field of accounting and finance. Related materials, journal, periodicals, and relevant material were consulted in the course of this study. 


\subsection{Conclusion and Recommendations}

\subsection{Conclusion}

This study had carried an extensive review of insolvency and the role of auditors. Prior studies of scholars' divergent opinions and mixed reactions were presented in the study. While some scholars think the role of auditor in insolvency is not good enough not to have dictated early signal of insolvency and offer professional advice to averted possible insolvency and or bankruptcy. This school of thought posited that some auditors are not thorough as due diligence and care were not conducted in most audit programs. Some opined that some auditors are accomplices and co-conspirators who are ready to compromise their independence at a mere perk gift from their clients' management to cover some unethical activities. On the contrary, some other schools of thought thinks that the auditors are rather a victim of circumstances who found themselves in between the financial and audit dilemma of poor structured auditing standards, limitations of the standards that guide audit procedures and processes. However from the perspective of the researcher, the auditors are the victims of standards which are not comprehensive enough to carter for the need and expectations of all the stakeholders.

\subsection{Recommendations}

The study recommended that auditors should exercise more professional care and carry out full due diligence especially where the auditor perceives some breakdown of auditing principles. The auditing firms should carry out extensive training of its audit staff with respect to the peculiarity of a new assignment as each audit assignment comes with its uniqueness, audit liabilities, and complexities. The International Auditing Standards Board should considers and accommodate the stakeholders' perceptions and expectations and make auditing standards more comprehensive. Special standards are issued to carter for some sensitive issues like fraud cases, insolvency, profitability, and bankruptcy on a going concern status for a special report in the auditor's report. 


\section{References}

Altman, E. I. (2018). Applications of distress prediction models: What have we learned after 50 years from the Z-Score models? International Journal of Financial Studies, 6(5), 1-12.

Altman, E. I., Małgorzata, I.., Erkki, K. L., \& Arto Suvas, A. (2017).Financial distress prediction in an international context: A review and empirical analysis of Altman's Z-Score model. Journal of International Financial Management and Accounting, 28(4), 131-147.

Amani, F. A., \& Fadlalla, A. M. (2017). Data mining applications in accounting: A review of the literature and organizing framework. International Journal of Accounting Information Systems, 24(6), 32-58.

Amin, Keval, Jagan Krishnan, and Joon Sun Yang. 2014. Going concern opinion and cost of equity. Auditing: A Journal of Practice and Theory, 33(5), 1-39.

Bauweraerts, J. (2016). Predicting bankruptcy in private firms: Towards a stepwise regression procedure. International Journal of Financial Research, 7(1), 147-53.

Beaver, W, H. 1968. Alternative accounting measures as predictors of failure. The Accounting Review, 43(3), 113-22.

Bellovary, J. L., Don, E. G., \& Akers, M. D. (2007). A review of bankruptcy prediction studies: 1930 to present. Journal of Financial Education, 33(1), 1-42.

Berglund, N. R., Eshleman, J. D., \& Guo, P. (2018). Auditor size and going concern reporting. Auditing. A Journal of Practice \& Theory, 37(91), 1-25.

Cao, Jian, Thomas R. Kubick, and Adi N.S. Masli. 2017. Do corporate payouts signal going-concern risk for auditors? Evidence from audit reports for companies in financial distress. Review of Quantitative Finance and Accounting, 49(2), 599-631.

Carson, E., Neil, E., \& Zhang, Y. (2016). Trends in auditor reporting in Australia: A synthesis and opportunities for research. Australian Accounting Review, 26(1), 26-42.

Cenciarelli, Velia, G., Giulio, G., \& Allegrini, M. (2018). External audit and bankruptcy prediction. Journal of Management and Governance, 22(2), 1-28.

Chen, Y., Yang, C., \& Yi-Fang, Y. (2020). Higher academic qualifications, professional training and operating performance of audit firms. Sustainability, 12(12), 1-20. Doi: 10.3390/su12031254.

Chen, Ch., Xiumin, M.., \& Xin, W. (20130. Insider trading, litigation concerns, and auditor going-concern opinions. The Accounting Review, 88(1), 36-53.

Chen, P. F., He, S., Ma,Z., \& Derrald , S. (2016). The information role of audit opinions in debt contracting. Journal of Accounting and Economics, 61(7). 121-44.

Chen, Y., John Daniel Eshleman,, and Jared S. Soileau. 2017. Business strategy and auditor reporting. Auditing: A Journal of Practice \& Theory 36: 63-86.

Cultrera, L., \& Xavier, B. (2016). Bankruptcy prediction: The case of Belgian SMEs. Review of Accounting and Finance, 15(2), 1-23.

Eutsler, J., Nickell, E. B., \& Sean, W., \& G. Robb, G. (2016). Fraud risk awareness and the likelihood of audit enforcement action. Accounting Horizons, 30(2), 379-92.

Feng, M., \& Chan, L. (2014). Are auditors professionally skeptical? Evidence from auditors' going-concern opinions and management earnings forecasts. Journal of Accounting Research, 52, 1061-1085.

Geiger, M. A., Raghunandan, K., \& William Riccardi, W. (2014). The global financial crisis: US bankruptcies and going-concern audit opinions. Accounting Horizons 28, 59-75.

Goncharov, I., Werner, J. R., Zimmermann, J. (2009). Legislative demands and economic realities: Company and group accounts compared. International Journal of Accounting, 4(4), 334-362.

Guiral, A., Rodgers, W., Ruiz, E., \& Gonzalo, J. A. (2018). Ethical dilemmas in auditing: Dishonesty or unintentional bias? Journal of Business and Ethics, 9(1), 151-166.

Hardle, W. K., Rouslan, A. M. \& Dorothea, S. (2004). Rating Companies with Support Vector Machines. German Institute for Economic Research, Discussion Papers, No. 416. Berlin: German Institute.

Ittonen, K., Per, C. T., \& Wong, L. (2017). Substantial doubt and the entropy of auditors' going concern modifications. Journal of Contemporary Accounting \& Economics, 13(1), 134-47.

Jiang, P., Hu, Y. C., Wang, W., Jiang, H., \& Wu, G. (2020). Interval grey prediction models with forecast combination for energy demand forecasting. Mathematics, 6(8), 1-15.

Kausar, A., \& Lennox, C. S. (2017). Balance sheet conservatism and audit reporting conservatism. Journal of Business Finance \& Accounting 44(4), 897-924.

Kausar, A., Richard, J., Christine, E. L., \& Tan. (2017). Legal regimes and investor response to the auditor's going-concern opinion. Journal of Accounting, Auditing \& Finance, 32(1), 40-72.

Koh, W., \& Kin-Wai, L. (2017). Do Auditors Recognize Managerial Risk-Taking Incentives? International Journal of Business, 22(4). 206-29.

Korol, Tomasz. 2013. A new Approach to Ratio Analysis in an Enterprise. Warszawa: Wolters Kluwer Polska. International Studies of Accounting, 2(12), 1-21.

Lioukas, C. S., \& Reuer, J. J. (2015). Isolating trust outcomes from exchange relationships: Social exchange and learning benefits of priorties in alliances. Academy and Management Journal, 5(8), 1826-1847. 
Martin, A., Lakshmi, T. M., \& Venkastesan, V. P. (2014). A framework to develop qualitative bankruptcy prediction rules Using Swarm Intelligence. St. Joseph's Journal of Humanities and Science 2(1), 73-81.

McEvily, B., Zaheer, A., \& Kamal, D. F. (2017). Mutual and exclusive: Dyadic sources of trust in interorganizational exchange. Organizational Science, 28(8), 74-92.

Munoz-Izquierdo, N., Camacho-Miñano, M., Segovia-Varga, M., \& Pascual-Ezama, D. (2019). Is the external audit report useful for bankruptcy prediction? Evidence using artificial intelligence. International Journal Financial Studies, 7(20), 1-23. Doi:10.3390/ijfs7020020

Ohlson, J. A. (1980). Financial ratios, and the probabilistic prediction of bankruptcy. Journal of Accounting Research, 18(2), 109-31

Okpala, K. E. (2015). Stamatis generic model and audit quality in Nigeria. The Journal of Social Sciences Research, 1(8), 94-101.

Ole-Kristian, H., Hu, D., \& Zhao, W. (2017). Third-party consequences of short-selling threats: The case of auditor behavior. Journal of Accounting and Economics, 63, 479-98.

Opoku, A. K., \& Chizema Amon, C. (2017). Board audit committee and corporate insolvency. Journal of Applied Accounting Research, $18(9), 298-316$.

Philippe, D. J. (2015). Bankruptcy prediction using terminal failure processes. European Journal of Operational Research, 24(2), 286303.

Prusak, (2018). Review of research into enterprise bankruptcy prediction in selected Central and Eastern European Countries. International Journal of Accounting Studies, 6(16), 1-21.

Read, W. J., \& Yezegel, A. (2016). Auditor tenure and going concern opinions for bankrupt clients: Additional evidence. Auditing: $A$ Journal of Practice and Theory, 35(1), 163-79.

Read, W. J., \& Ari Yezegel, A. (2018). Going-concern opinion decisions on bankrupt clients: Evidence of long-lasting auditor conservatism? Advances in Accounting 40: 20-26.

Pedrosa R., Áurea, M., \& Francisco L. (2018). Auditors' response to the global financial crisis: Evidence from Spanish non-listed companies. Spanish Journal of Finance and Accounting, 47, 40-53.

Rodgers, W., Guiral, A., \& Gonzalo, J. A. (2009). Different pathways that suggest whether auditors' going concern opinions are ethically based. Journal of Business and Ethics, 8(6), 347-361.

Rodgers, W., Guiral, A., \& Gonzalo, J. A. (2019) Trusting/distrusting auditors' opinions. Sustainability, 19(2), 1-21

Sanchez-Serrano, J. R., Alaminos, D., Francisco, G. ., \& Callejón-Gil, A. M. (2020). Predicting audit opinion in consolidated financial statements with artificial neural networks. Mathematics, 8(3), 1-14. Doi: 10.3390/math8081288.

Seising, R. (2018). The Emergence of fuzzy sets in the decade of the perceptron-lotfi, a. Zadeh's and Frank Rosenblatt's research work on pattern classification. Mathematics $2018,6,110$.

Shin, K., \& Lee, Y. (2012). A genetic algorithm application in bankruptcy prediction modelling. Expert systems with applications, 23(1), $321-28$.

Sotti, F. ((2018). The value relevance of consolidated \& separate financial statements: Are non-controlling interests relevant? African Journal of Business and Management, 12(3), 329-333.

Zavgren, C. (1983). The prediction of corporate failure: The state of the art. Journal of Accounting Literature, 2(2), 1-38. 


\section{Main text}

(10 pt) Here introduce the paper, and put a nomenclature if necessary, in a box with the same font size as the rest of the paper. The paragraphs continue from here and are only separated by headings, subheadings, images and formulae. The section headings are arranged by numbers, bold and $10 \mathrm{pt}$. Here follows further instructions for authors.

\begin{tabular}{|ll|}
\hline Nomenclature \\
\hline A & radius of \\
B & position of \\
\hline C & further nomenclature continues down the page inside the text box \\
\hline
\end{tabular}

\subsection{Structure}

For this Procedia the files must be in MS Word format only and should be formatted for direct printing. Figures and tables should be embedded and not supplied separately. Please make sure that you use as much as possible normal fonts in your documents. Special fonts, such as fonts used in the Far East (Japanese, Chinese, Korean, etc.) may cause problems during processing. To avoid unnecessary errors you are strongly advised to use the 'spellchecker' function of MS Word. Follow this order when typing manuscripts: Title, Authors, Affiliations, Abstract, Keywords, Main text (including figures and tables), Acknowledgements, References, Appendix. Collate acknowledgements in a separate section at the end of the article and do not include them on the title page, as a footnote to the title or otherwise.

Bulleted lists may be included and should look like this:

- First point

- Second point

- And so on

Ensure that you return to the 'Els-body-text' style, the style that you will mainly be using for large blocks of text, when you have completed your bulleted list.

Please do not alter the formatting and style layouts which have been set up in this template document. As indicated in the template, papers should be prepared in single column format suitable for direct printing onto A4 paper (192mm x $262 \mathrm{~mm}$ ). Do not number pages on the front, as page numbers will be added separately for the preprints and the Proceedings. Leave a line clear between paragraphs. All the required style templates are provided in this document with the appropriate name supplied, e.g. choose 1. Els1st-order-head for your first order heading text, els-abstract-text for the abstract text etc. 


\subsection{Tables}

All tables should be numbered with Arabic numerals. Headings should be placed above tables, left justified. Leave one line space between the heading and the table. Only horizontal lines should be used within a table, to distinguish the column headings from the body of the table, and immediately above and below the table. Tables must be embedded into the text and not supplied separately. Below is an example which authors may find useful.

Table 1. An example of a table

\begin{tabular}{lll}
\hline An example of a column heading & Column A $(t)$ & Column B $(T)$ \\
\hline And an entry & 1 & 2 \\
And another entry & 3 & 4 \\
And another entry & 5 & 6 \\
\hline
\end{tabular}

\subsection{Construction of references}

References should be added at the end of the paper, and its corresponding citation will be added in the order of their appearance in the text. Authors should ensure that every reference in the text appears in the list of references and vice versa. Indicate references by Clark et al., 1962 or Deal and Grove, 2009 or Fachinger, 2006 in the text. The actual authors can be referred to, but the reference citation(s) must always be given.

Some examples of how your references should be listed are given at the end of this template in the 'References' section, which will allow you to assemble your reference list according to the correct format and font size.

\subsection{Section headings}

Section headings should be left justified, with the first letter capitalized and numbered consecutively, starting with the Introduction. Sub-section headings should be in capital and lower-case italic letters, numbered 1.1, 1.2, etc, and left justified, with second and subsequent lines indented. You may need to insert a page break to keep a heading with its text.

\subsection{General guidelines for the preparation of your text}

Avoid hyphenation at the end of a line. Symbols denoting vectors and matrices should be indicated in bold type. Scalar variable names should normally be expressed using italics. Weights and measures should be expressed in SI units. Please title your files in this order conferenceacrynom_authorslastname.pdf

\subsection{Footnotes}

Footnotes should be avoided if possible. Necessary footnotes should be denoted in the text by consecutive superscript letters. The footnotes should be typed single spaced, and in smaller type size (8pt), at the foot of the page in which they are mentioned, and separated from the main text by a short line extending at the foot of the column. The 'Els-footnote' style is available in this template for the text of the footnote. 


\section{Author Artwork}

All figures should be numbered with Arabic numerals $(1,2, \ldots \mathrm{n})$. All photographs, schemas, graphs and diagrams are to be referred to as figures. Line drawings should be good quality scans or true electronic output. Low-quality scans are not acceptable. Figures must be embedded into the text and not supplied separately. Lettering and symbols should be clearly defined either in the caption or in a legend provided as part of the figure. Figures should be placed at the top or bottom of a page wherever possible, as close as possible to the first reference to them in the paper.

The figure number and caption should be typed below the illustration in 8pt and left justified. For more guidelines and information to help you submit high quality artwork please visit: http://ijrp.org/page/instruction. Artwork has no text along the side of it in the main body of the text. However, if two images fit next to each other, these may be placed next to each other to save space, see Fig 1 . They must be numbered consecutively, all figures, and all tables respectively.

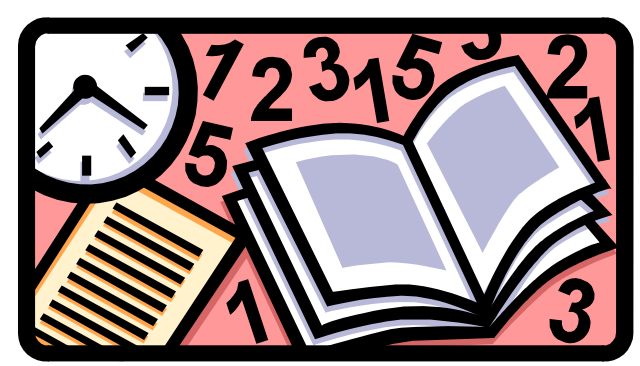

Fig. 1. (a) first picture; (b) second picture

Equations and formulae should be typed and numbered consecutively with Arabic numerals in parentheses on the right hand side of the page (if referred to explicitly in the text),

$$
\rho=\frac{\vec{E}}{J_{C}(T=\text { const. }) \cdot\left(P \cdot\left(\frac{\vec{E}}{E_{C}}\right)^{m}+(1-P)\right)}
$$

They should also be separated from the surrounding text by one space.

\section{Acknowledgements}

These and the Reference headings are in bold but have no numbers. Text below continues as normal.

\section{References}

Clark, T., Woodley, R., De Halas, D., 1962. Gas-Graphite Systems, in "Nuclear Graphite” R. Nightingale, Editor. Academic Press, New York, p. 387.

Deal, B., Grove, A., 1965. General Relationship for the Thermal Oxidation of Silicon, Journal of Applied Physics 36, p. 3770.

Deep-Burn Project: Annual Report for 2009, Idaho National Laboratory, Sept. 2009. 
Fachinger, J., den Exter, M., Grambow, B., Holgerson, S., Landesmann, C., Titov, M., Podruhzina, T., 2004."Behavior of spent HTR fuel elements in aquatic phases of repository host rock formations," $2^{\text {nd }}$ International Topical Meeting on High Temperature Reactor Technology. Beijing, China, paper \#B08.

Fachinger, J., 2006. Behavior of HTR Fuel Elements in Aquatic Phases of Repository Host Rock Formations. Nuclear Engineering \& Design 236, p. 54.

\section{Appendix A. An example appendix}

Authors including an appendix section should do so after References section. Multiple appendices should all have headings in the style used above. They will automatically be ordered A, B, C etc.

\section{A.1. Example of a sub-heading within an appendix}

There is also the option to include a subheading within the Appendix if you wish. 